CASE REPORTS

\title{
Roundworm granuloma of the anterior abdominal wall
}

\author{
P. T. ChandRASOMA \\ M.D.
}

\author{
SRIAN DE Silva* \\ M.B., F.R.C.S.
}

\author{
M. Yoganathan \\ D.C.P., Ph.D., F.R.C.Path.
}

Faculty of Medicine, University of Sri Lanka and *Badulla Hospital, Sri Lanka

\begin{abstract}
Summary
A case of migration of a gravid female roundworm into the peritoneal cavity is reported. The presenting feature, a lump in the anterior abdominal wall, has not previously been documented. Fertilized ova of the worm were found in miliary peritoneal granulomata, and showed development up to the eight-cell stage.
\end{abstract}

\section{Introduction}

Migration of Ascaris lumbricoides (the roundworm) from its normal habitat in the intestinal lumen into the peritoneal cavity is a rare complication of ascariasis. A case is reported where the worm, after such migration, settled beneath the parietal peritoneum of the abdominal wall and deposited its ova in the peritoneal cavity. The reaction against the worm resulted in the formation of a granuloma which was palpable as a lump in the anterior abdominal wall, a presenting feature that has not previously been recorded in ascariasis. The patient also had a granulomatous peritonitis due to the ova.

\section{Case report}

A 4-year-old boy was admitted to the surgical casualty ward with a history of abdominal pain and vomiting of one day's duration. He had had a similar attack one week previously, but this had disappeared the same day. On examination, he was in pain but afebrile. The abdomen was slightly distended and a tender mass could be palpated in the left paraumbilical region. A tentative diagnosis of intussusception was made, and a laparotomy performed.

At surgery, a smooth, soft, reddish mass, measuring $8 \mathrm{~cm}$ by $2 \mathrm{~cm}$ was found adhering to the parietal

Correspondence: Dr P. T. Chandrasoma, Department of Pathology, Faculty of Medicine, University of Sri Lanka, Kynsey Road, Colombo 8, Sri Lanka. peritoneum of the anterior abdominal wall, corresponding to the mass which was palpated on external examination. There was no bowel adherent to the lump. There was no fluid in the peritoneal cavity, but numerous white nodules of $1-2 \mathrm{~mm}$ in size were seen on the serosa covering the liver, mesentery and small intestine. The liver was not enlarged. The small intestine appeared normal, except for the presence of numerous intralumenal roundworms. Specimens were taken for histology and the wound was closed. The child made an uneventful recovery.

Histological examination of the granuloma in the abdominal wall revealed fragments of a degenerated roundworm in the centre of an inflammatory mass (Fig. 1). The worm was identified by (a) the presence of numerous typical fertilized ova, measuring 72-90 $\mu \mathrm{m}$ in diameter, (b) remnants of its cuticle showing transverse striations (Fig. 2), and (c) remnants of its wall showing parallel bands of muscle fibres (Fig. 3). The granuloma contained lymphocytes, macrophages, giant cells, and a large number of eosinophils.

The miliary granulomata in the peritoneal cavity showed a similar reaction around ova in varying stages of degeneration (Figs 4-6).

\section{Discussion}

Granulomatous peritonitis due to roundworm ova was first described by Africa and Garcia (1936). Since then, several other cases have been reported. In the earlier reports, no adult worms were identified, and the mechanism by which the ova reached the peritoneal cavity was disputed (Cooray, 1951). In many later cases, as in the present report, degenerate fragments of adult roundworms have been identified in the peritoneal cavity. The intense inflammatory reaction probably destroys the worm 


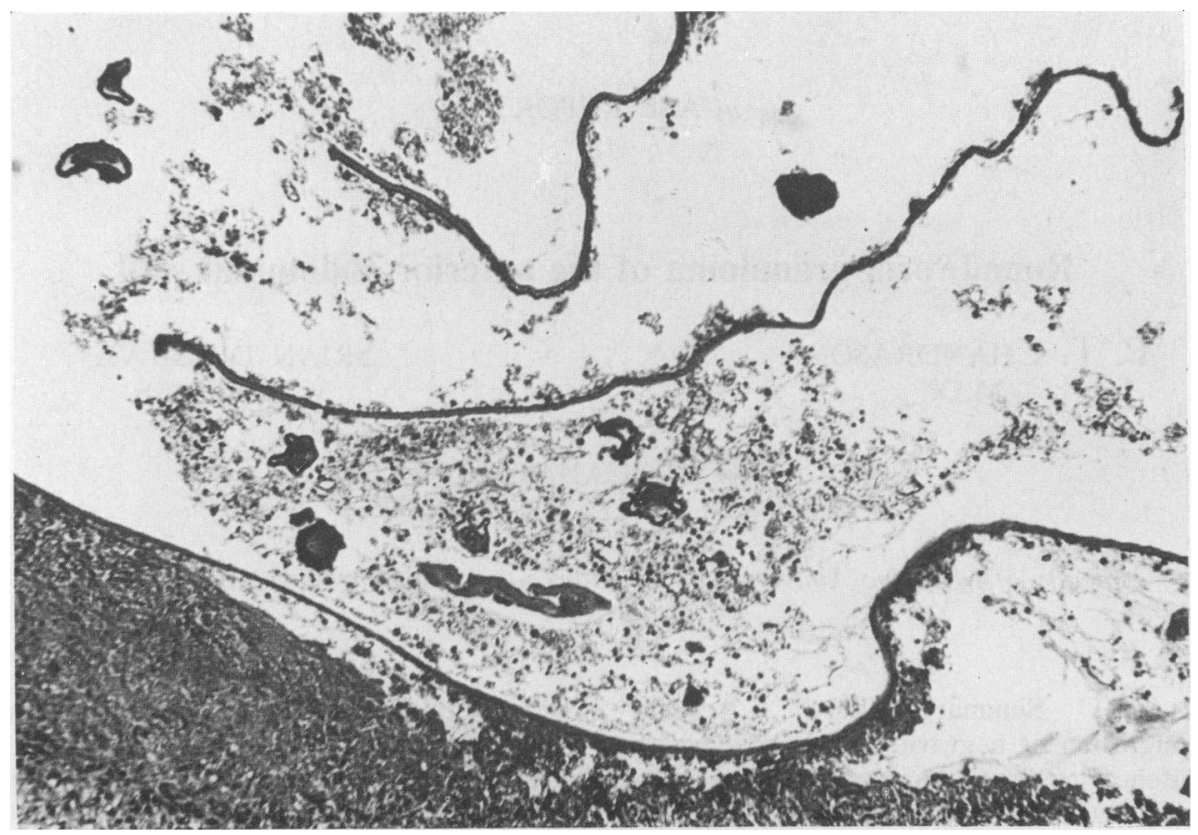

Fig. 1. Fragments of roundworm and its ova in the abdominal wall granuloma (HE, $\times 117)$.

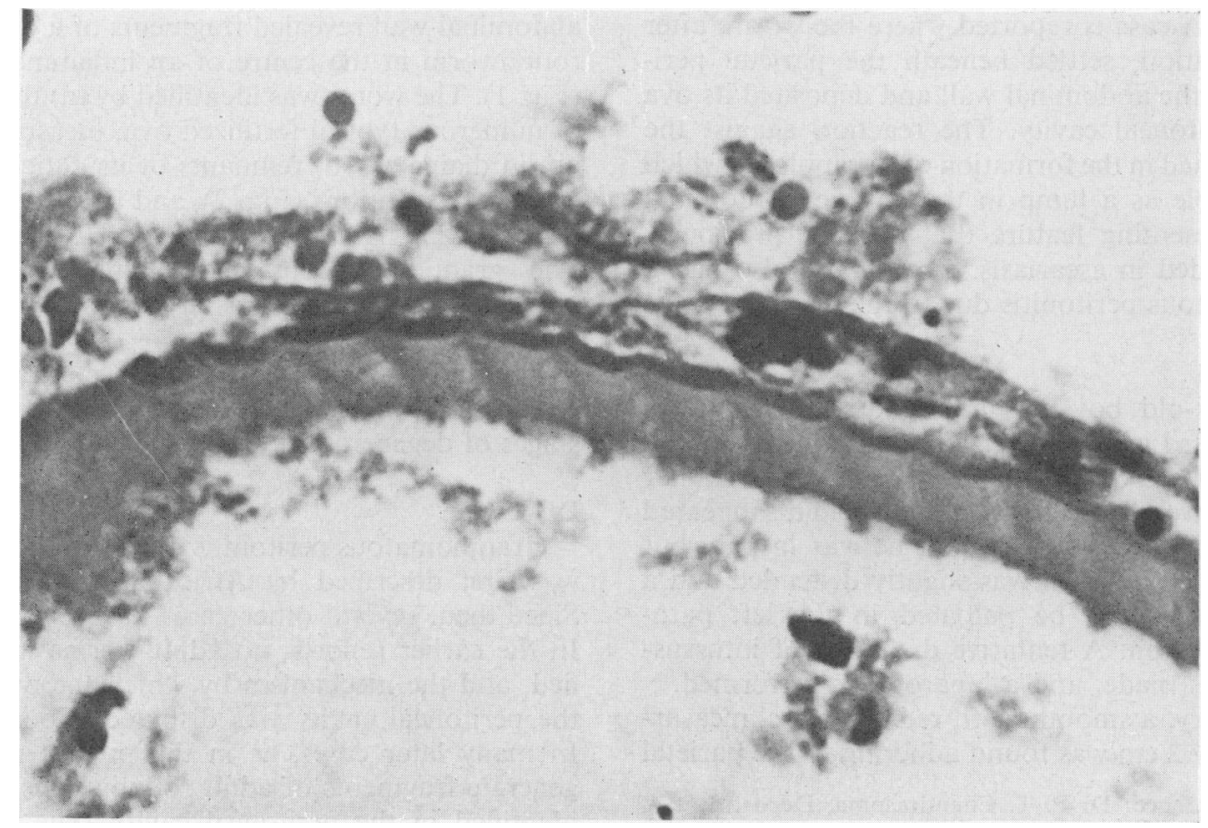

Fig. 2. Cuticle of the roundworm, showing transverse striations $(\mathrm{HE}, \times 825)$. 


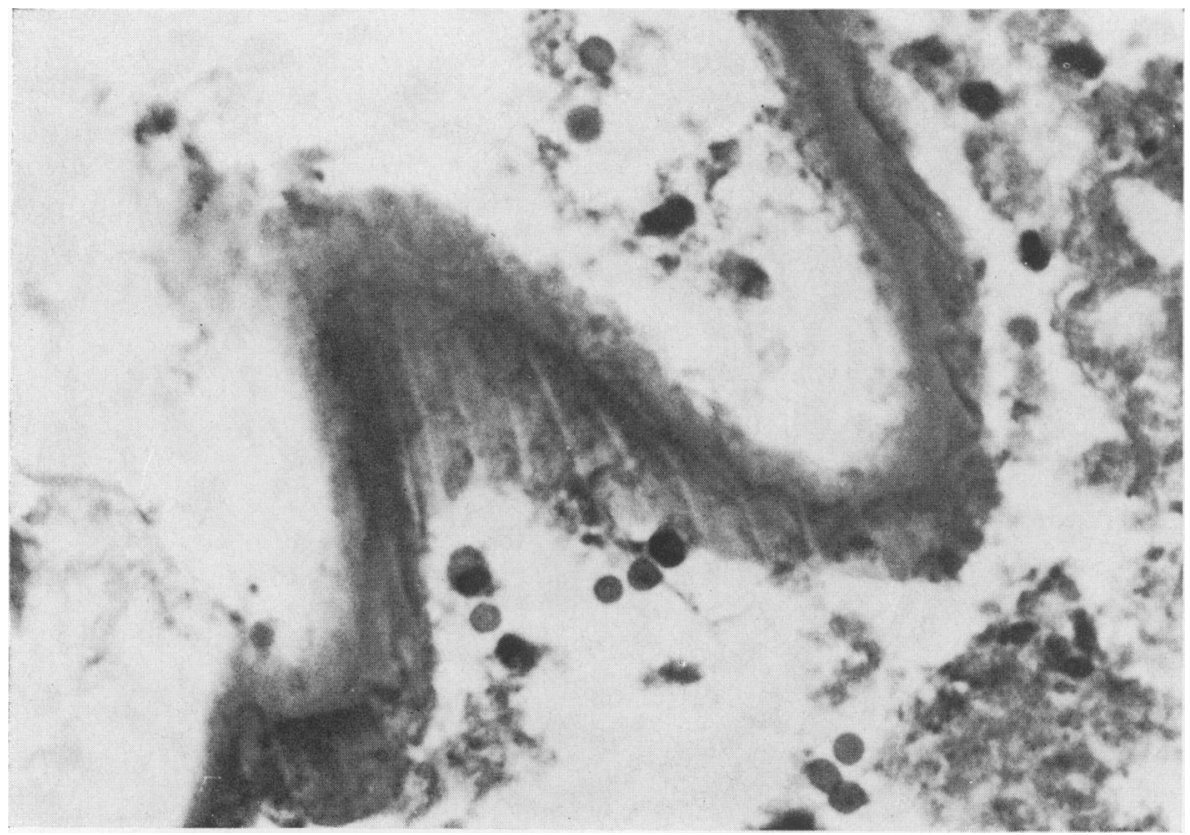

FIG. 3. Muscle bands in the wall of the worm $(\mathrm{HE}, \times 825)$.

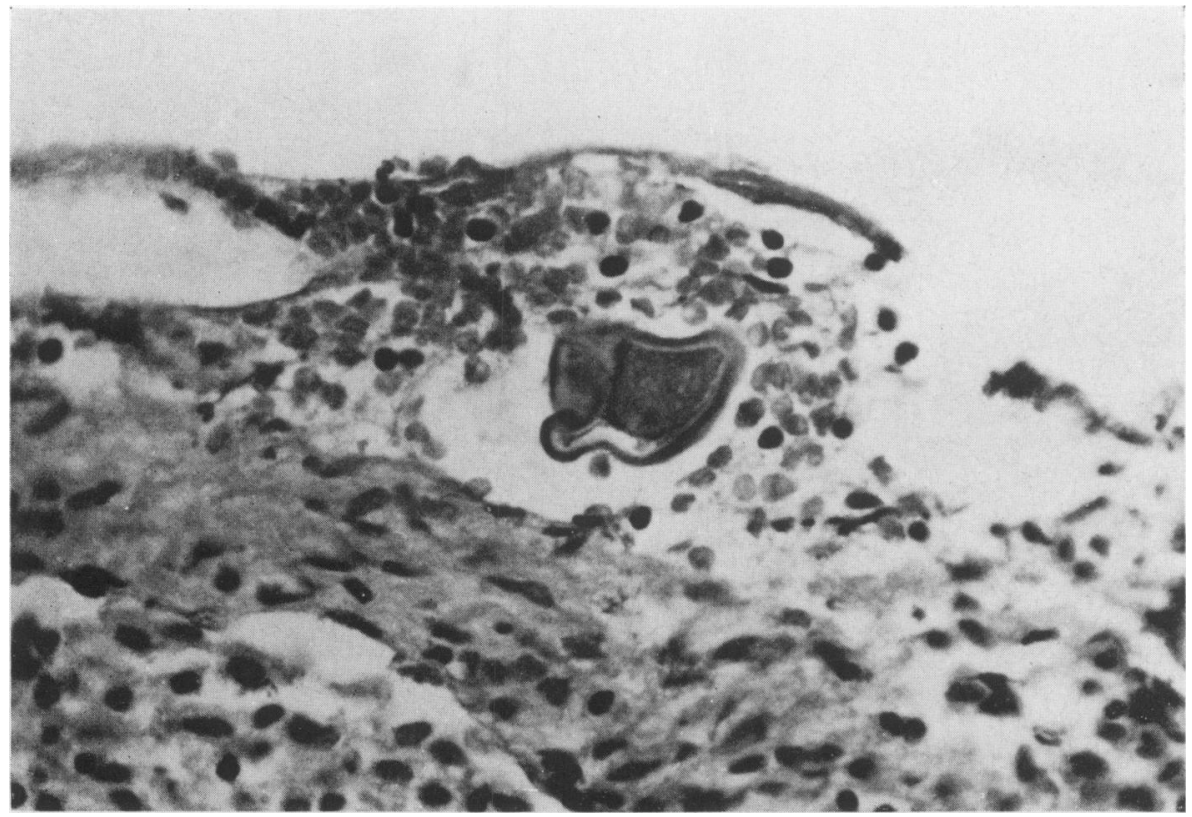

FIG. 4. Early peritoneal granuloma with red cells and a few lymphocytes around the roundworm ovum (HE, $\times$ 525). 


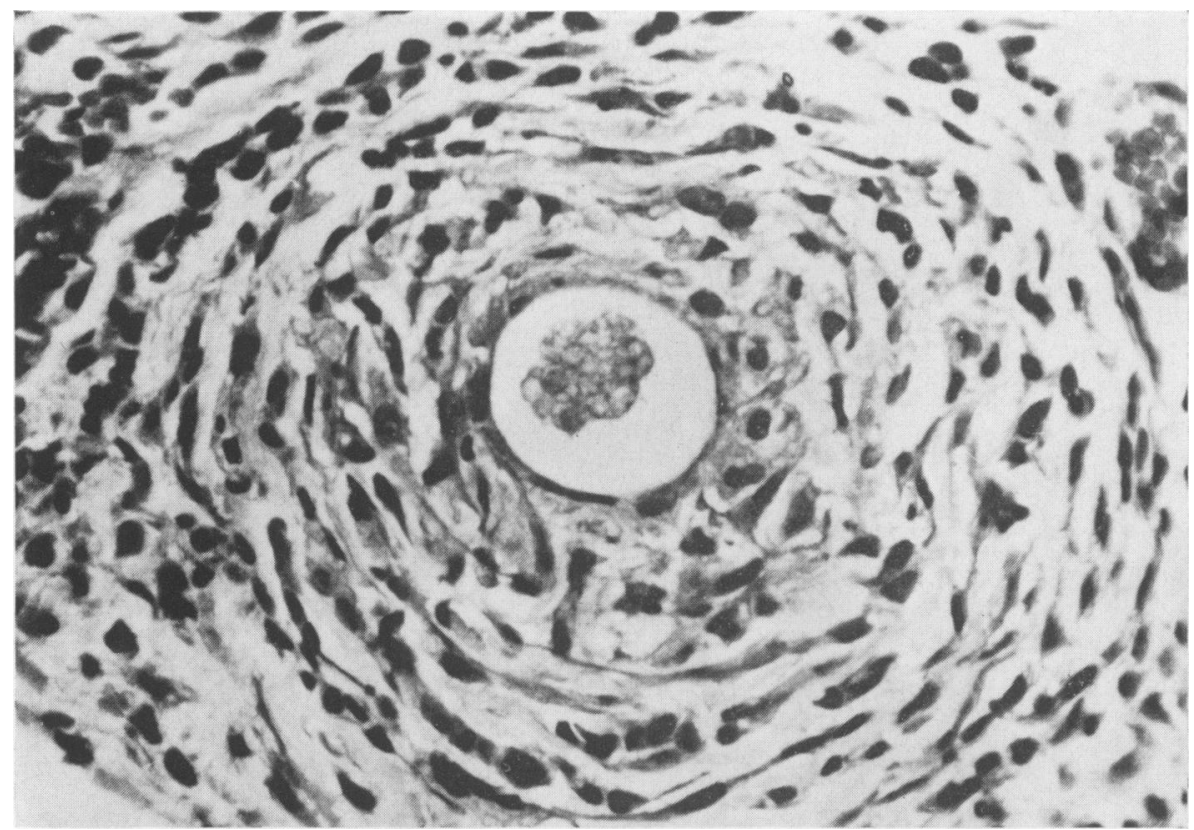

Fig. 5. Peritoneal granuloma with ovum in centre. The chitinous wall has been digested, and the ovum has segmented $(\mathrm{HE}, \times 525)$.

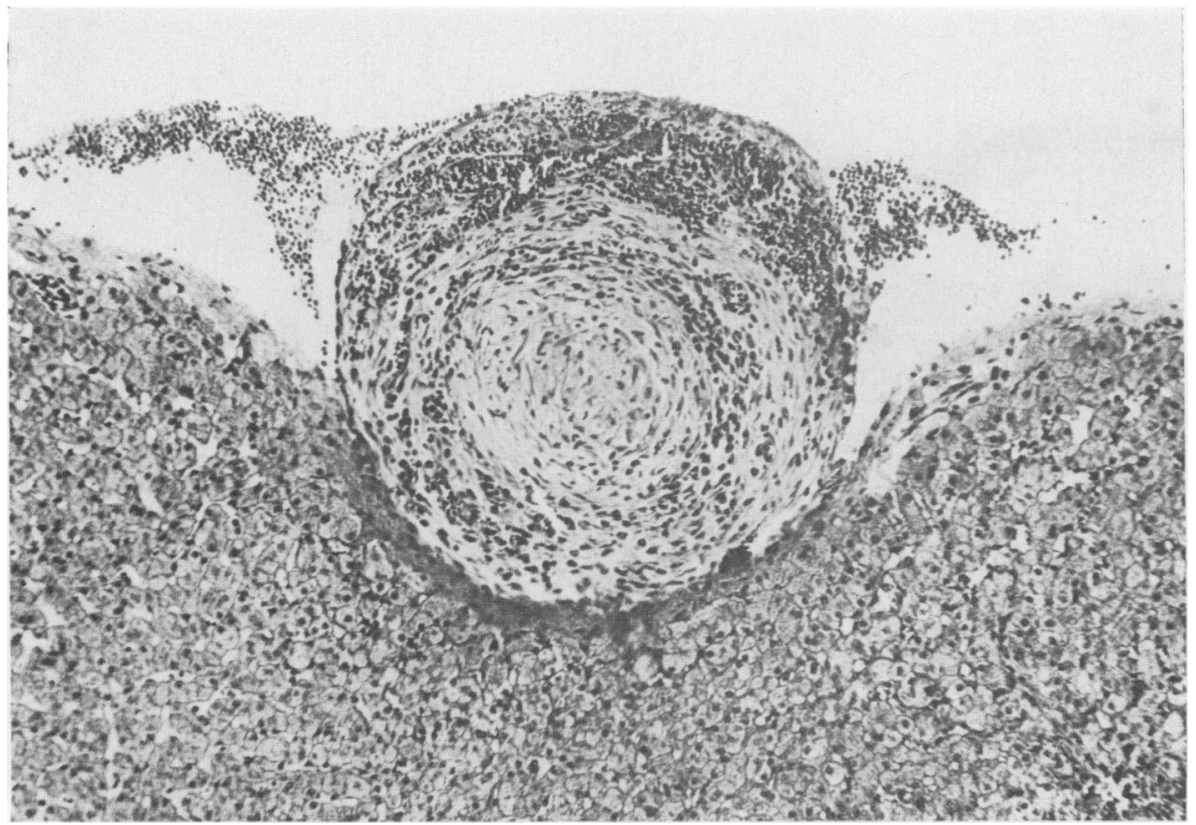

FIG. 6. Fibrotic granuloma on surface of liver. The ovum has disappeared $(\mathrm{HE}, \times 117)$. 
rapidly, and in this case, only its most resistant structures - the ova, cuticle and muscle bands were seen. These same features were reported by Teoh (1963) as important in identifying degenerate roundworms in the biliary tract.

The ova in the peritoneal cavity were fertilized ova. Fertilization occurs in the intestine, and the presence of fertilized ova is proof that the worm migrated to the peritoneal cavity from the intestinal lumen.

The mechanism of migration of the roundworm across the intestinal wall is uncertain. In many reported cases, an intestinal perforation has been present. Perforation of an inflamed appendix (Louw, 1966), typhoid ulcers (Dickson and Cole, 1964), and inflamed Meckel's diverticula (Paul and Goonewardene, 1953) have been known to release roundworms into the peritoneal cavity. In many cases, as in the present one, there has been no evidence of intestinal perforation, and it has been suggested that the roundworm has actively penetrated the intestinal wall. Girges (1934) suggested that the worm nibbles its way through the wall. However, the buccal apparatus of the roundworm is not denticulated, and nibbling does not seem likely. The penetration is probably a slow process which permits the intestine to seal itself behind the migrating worm.

The ova deposited in the peritoneal cavity lead to the formation of miliary granulomata (Figs 4-6). The chitinous wall of the ovum is quickly digested (Fig. 5), and after a variable interval, the ovum itself disappears (Fig. 6). Cooray and Panabokke (1960) demonstrated that roundworm ova disappear within three months after being introduced into the rat peritoneal cavity. This suggests that the entry of gravid roundworms into the peritoneal cavity produces a self-limiting illness for a period not exceeding three months.

The ova in the peritoneal granulomata showed segmentation up to the eight-cell stage (Fig. 5). Segmentation of fertilized ascarid ova does not occur in the $37^{\circ} \mathrm{C}$, anoxic environment of the human intestinal lumen. The findings in the present case indicate that the roundworm ovum can develop up to the eight-cell stage at body temperature. The oxygen supplied by the blood vessels in the inflammatory mass is probably sufficient to stimulate cleavage of the roundworm ovum.

\section{References}

AfricA, C.M. \& Garcia, E.Y. (1936) Embryonated eggs of Ascaris lumbricoides in the mesenteric tissue of man, with special reference to the possibility of auto-infestation. Journal of the Philippine Islands Medical Association, 16, 461.

COORAY, G.H. (1951) Embryonated eggs of Ascaris lumbricoides in the wall of a human hernial sac. Annals of Tropical Medicine and Parasitology, 45, 62.

Cooray, G.H. \& Panabokke, R.G. (1960) Granulomatous peritonitis caused by Ascaris ova. Transactions of the Royal Society of Tropical Medicine and Hygiene, 54, 358.

Dickson, J.A.S. \& Cole, G.J. (1964) Perforation of the terminal ileum: a review of 38 cases. British Journal of Surgery, 51, 893.

GIRGES, R. (1934) Pathology and complications of ascariasis. Journal of Tropical Medicine, 37, 296.

Louw, J.H. (1966) Abdominal complications of Ascaris lumbricoides infestation in children. British Journal of Surgery, 53, 510.

Paul, M. \& Goonewardene, D.F. De S. (1953) Acute Meckel's diverticulitis with roundworms in the peritoneal cavity. American Journal of Surgery, 85, 243.

TEOH, T.B. (1963) A study of gall stones and included worms in recurrent pyogenic cholangitis. Journal of Pathology and Bacteriology, 86, 123. 